University of Nebraska - Lincoln

DigitalCommons@University of Nebraska - Lincoln

Faculty Publications from the Department of Electrical \& Computer Engineering, Department Electrical and Computer Engineering

$11-15-2000$

\title{
Infrared switching electrochromic devices based on tungsten oxide
}

\author{
E. B. Franke \\ University of Nebraska-Lincoln, efranke3@unl.edu \\ C. L. Trimble \\ University of Nebraska-Lincoln \\ J. S. Hale \\ J. A. Woollam Co. \\ Mathias Schubert \\ University of Nebraska-Lincoln, mschubert4@unl.edu \\ John A. Woollam \\ University of Nebraska-Lincoln, jwoollam1@unl.edu
}

Follow this and additional works at: https://digitalcommons.unl.edu/electricalengineeringfacpub

Part of the Electrical and Computer Engineering Commons

Franke, E. B.; Trimble, C. L.; Hale, J. S.; Schubert, Mathias; and Woollam, John A., "Infrared switching electrochromic devices based on tungsten oxide" (2000). Faculty Publications from the Department of Electrical and Computer Engineering. 4.

https://digitalcommons.unl.edu/electricalengineeringfacpub/4

This Article is brought to you for free and open access by the Electrical \& Computer Engineering, Department of at DigitalCommons@University of Nebraska - Lincoln. It has been accepted for inclusion in Faculty Publications from the Department of Electrical and Computer Engineering by an authorized administrator of DigitalCommons@University of Nebraska - Lincoln. 


\title{
Infrared switching electrochromic devices based on tungsten oxide
}

\author{
E. B. Franke ${ }^{\text {a) }}$ \\ Center for Microelectronic and Optical Materials Research, and Department of Electrical Engineering, \\ University of Nebraska, Lincoln, Nebraska 68588-0511 and Institut für Oberflächenmodifizierung Leipzig \\ e.V., Permoserstrasse 15, 04318 Leipzig, Germany \\ C. L. Trimble \\ Center for Microelectronic and Optical Materials Research and Department of Electrical Engineering, \\ University of Nebraska, Lincoln, Nebraska 68588-0511 \\ J. S. Hale \\ J. A. Woollam Co., Inc., Suite 102, 645 M Street, Lincoln, Nebraska 68588 \\ M. Schubert and J. A. Woollam \\ Center for Microelectronic and Optical Materials Research, and Department of Electrical Engineering, \\ University of Nebraska, Lincoln, Nebraska 68588-0511
}

(Received 23 May 2000; accepted for publication 28 August 2000)

Different types of electrochromic devices for thermal emittance modulation were developed in the spectral region from mid- to far-infrared $(2-40 \mu \mathrm{m})$. In all devices polycrystalline and amorphous tungsten oxide have been used as electrochromic and ion storage layer, respectively. Two types of all-solid-state devices were designed, one with a metal grid for the top and bottom electrode deposited on a highly emissive glass substrate, and another with a top metal grid electrode and a highly reflecting bottom metal electrode layer. Tantalum oxide is used as an ion conductor in both device types. The third device type consists of a polymeric ion conductor. All solid-state constituent layers were grown by either reactive or nonreactive dc or rf magnetron sputtering in a high vacuum environment. Modulation of the emittance is accomplished by reversible insertion of Li ions into polycrystalline $\mathrm{WO}_{3}$ by applying and switching a small voltage across the structure. Spectrally dependent measured reflectance modulation of the device has been used to determine the device emissivity modulation with respect to the blackbody emissivity spectra at $300 \mathrm{~K}$. Best device performance was found in both solid-state devices showing an emissivity modulation of about $20 \%$. (C) 2000 American Institute of Physics. [S0021-8979(00)01623-6]

\section{INTRODUCTION}

Electrochrochromic materials have the peculiarity to change reversibly the optical properties (refractive index $n$, extinction coefficient $k$ ) upon insertion and extraction of small ions after application of small voltages. Many materials are known to show electrochromic behavior, and tungsten trioxide is the most extensively studied electrochromic material. This electrochromic behavior can be used for many applications. In recent years electrochromic devices (ECD) have been primarily investigated for use in the visible spectral region. Applications include transmittance modulation of sunlight control window glazings for buildings (smart windows), optical displays, and reflectance modulating automobile rear-view mirrors. ${ }^{1}$

Electrochromic devices can also be used for surface emissivity control [emissivity modulation devices (EMD)]. Surface emissivity characteristics are represented by the blackbody spectra at a defined temperature. EMDs are especially of interest for thermal control in satellites. ${ }^{2-4}$ Thermal control of satellites is accomplished by balancing the energy dissipated by satellite electrical components against the energy emitted as IR radiation. ${ }^{5}$ Satellite emittance is charac-

\footnotetext{
${ }^{a)}$ Electronic mail: franke@engrs.unl.edu
}

terized by a blackbody spectrum at $T=300 \mathrm{~K}$ which has its intensity maximum near $10 \mu \mathrm{m}$, if the satellite temperature is aimed at room temperature. The EMD should have the highest dynamic modulation in this spectral region.

Polycrystalline tungsten oxide can be used as an electrochromic layer for infrared EMDs. According to Goldner et al., and Cogan et al. ${ }^{6-8}$ the emittance modulation occurs by varying the concentration of free electrons during element oxidation and reduction upon ion insertion and extraction, respectively. Therefore the change in the emittance is controlled by reflectance modulation. Amorphous tungsten oxide can be used as an ion storage layer in EMDs. The amorphous electrochromic material is usually transparent in a wide IR spectral region, regardless of the inserted ion concentration. ${ }^{9}$

EMDs are multilayered, and structured as follows: substrate/transparent electrode/ion storage layer/ion conductor/electrochromic layer/transparent electrode. In our devices small ions (typically $\mathrm{H}^{+}$or alkali ions) are introduced into the device structure via an electrochemical process. The ions are able to move from the electrochromic into the ion storage layer and back again, driven by a voltage applied between the electrodes. Electrochromic and ion storage layers can be of complementary electrochromic behavior, but the ion storage layer should be at least optically stable upon ion insertion/extraction. Electrochromism is 
complementary: The electrochromic layer is in its colored (bleached) state, and the ion storage layer is in its bleached (colored) state after ion insertion (extraction). Here, bleached and colored refer to the high and low optical transmission state of the material, respectively. The material quality of the ion conductor plays an important role for device performance. This layer should be a good conductor for small ions and a barrier for electrons. Electrochromic devices which operate in the visible to near-infrared spectral region (0.4$2.4 \mu \mathrm{m}$ ) are already commercially available.

So far electrochromic devices for the infrared (IR) especially for spectral regions at higher wavelength than the sun thermal emittance spectra have been much less investigated than electrochromics for the visible spectral region applications. ${ }^{10,11}$ This may be due to special requirements needed for devices operating in the IR. For instance electrode materials transparent to visible light [indium tin oxide (ITO)] are highly reflective in the IR spectral region. This is directly related to the free carrier concentration of the material. Typically electrodes for the IR consist of highly conducting metal grids having at least $90 \%$ transmittance. Two different types of emittance modulation devices have been suggested. One type proposed by Baucke et al. ${ }^{12}$ uses a highly reflecting bottom electrode and a highly transmitting top metal grid electrode. Here the emittance modulation is related to the reflectance modulation of the device. Topart et al. ${ }^{13}$ and Trimble et al. ${ }^{14}$ reported on modified devices of this general type, using polymers as ion conducting materials.

Cogan et al. ${ }^{15}$ designed an emittance modulation device using two IR transparent electrode grids as bottom and top electrodes. The bottom electrode was deposited on a highly emissive substrate and a polymer was used as an ion conductor.

In this article we report on the structural design of three different EMD types, two all-solid state devices, and one polymer based device, as follows:

(1) An all-solid-state device with metal grids as bottom and top electrode materials on a highly emissive glass substrate.

(2) An all-solid-state device with a highly reflecting bottom metal electrode and a transparent top metal grid electrode.

(3) A polymer ion conductor based device using a AMPS/DMA copolymer saturated with $\mathrm{LiClO}_{4}$. The polymer devices also contained diamondlike carbon (DLC) as antireflecting coatings on top of the slightly doped silicon electrode.

For all devices, polycrystalline (c) $\mathrm{Li}_{x} \mathrm{~W}_{1-x} \mathrm{O}_{3}$ and amorphous (a) $\mathrm{Li}_{x} \mathrm{~W}_{1-x} \mathrm{O}_{3}$ (or $\mathrm{NiO}$ ) were used as the electrochromic and an ion storage layer, respectively. Tantalum oxide is used as an ion conductor in all-solid state devices. All constituent layers were deposited as single films on silicon or glass substrates and characterized by $\mathrm{x}$-ray diffraction and variable angle spectroscopic ellipsometry to obtain crystal structure and optical properties. The operational properties were investigated for emittance modulation in the spectral region from 2 to $40 \mu \mathrm{m}$. The devices were based on reflectivity/emissivity modulation. We show results of simulated optical modulation for specific device structures. Cal-
TABLE I. Growth parameters used for electrochromic device constituents deposition.

\begin{tabular}{lcccccr}
\hline \hline $\begin{array}{l}\text { Thin } \\
\text { film }\end{array}$ & Deposition & $\begin{array}{c}p \\
(\mathrm{mT} \text { Torr })\end{array}$ & $\begin{array}{c}t \\
\left({ }^{\circ} \mathrm{C}\right)\end{array}$ & $\begin{array}{c}f_{\mathrm{Ar}} \\
(\mathrm{sccm})\end{array}$ & $\begin{array}{c}f_{\mathrm{O}_{2}} \\
(\mathrm{sccm})\end{array}$ & $\begin{array}{c}d \\
(\mathrm{~nm})\end{array}$ \\
\hline $\mathrm{ITO}$ & $45 \mathrm{~W}(\mathrm{dc})$ & 5 & 25 & 20 & $\cdots$ & 40 \\
$\mathrm{Al}$ & $40 \mathrm{~W}(\mathrm{dc})$ & 5 & 25 & 20 & $\cdots$ & 40 \\
$c-\mathrm{WO}_{3}$ & $35 \mathrm{~W}(\mathrm{dc})$ & 15 & 375 & 35 & 4.5 & 160 \\
$a-\mathrm{WO}_{3}$ & $35 \mathrm{~W}(\mathrm{dc})$ & 15 & 25 & 35 & 4.5 & 160 \\
$\mathrm{Ta}_{2} \mathrm{O}_{5}$ & $100 \mathrm{~W}(\mathrm{rf})$ & 13 & 375 & 20 & 7 & 350 \\
\hline \hline
\end{tabular}

culations were performed prior to device manufacturing as discussed in Refs. 2 and 16. The reflectance modulation was measured in the spectral region from 2 to $40 \mu \mathrm{m}$.

The spectrally dependent emittance modulation $\Delta E$ of the device was obtained from the experimentally measured reflectance modulation. The emittance of a nontransmitting device is defined $E=1-R$ ( $R=$ reflectance). The emissivity $\epsilon$ of the device in its different states (bleached, colored) relative to the blackbody spectra at $T=300 \mathrm{~K}$ is given by:

$$
\epsilon=\frac{\int_{\lambda_{1}}^{\lambda_{2}}[1-R(\lambda)] M_{b}(\lambda, T) d \lambda}{\int_{\lambda_{1}}^{\lambda_{2}} M_{b}(\lambda, T) d \lambda},
$$

where $R(\lambda)$ is the measured reflectance and $M_{b}(\lambda, T)$ is the blackbody spectral emittance. In this calculation the temperature was fixed at $300 \mathrm{~K}$, and $\lambda_{1}$ and $\lambda_{2}$ were 2 and 40 $\mu \mathrm{m}$, respectively. There are two important values characterizing the performance of an electrochromic device for thermal control. The device emissivity modulation $\epsilon_{\text {modulation }}$ and the ratio $\epsilon_{\text {ratio }}$ are given by the difference and the quotient of the emissivity in the devices high and low emittance state. For practical applications a low modulating device with a high ratio could be used as well as a high modulation device with a low ratio. Although for thermal emittance control a larger area of the object needs to be coated with an electrochromic active layer stack having a smaller modulation and a higher ratio than for a high modulation layer ensemble.

\section{EXPERIMENT}

The thin film all-solid state device constituent layers were deposited by dc or rf magnetron sputtering in a highvacuum (HV) deposition chamber with a typical background pressure of $3 \times 10^{-6}$ Torr. Glass slides were used as the substrate material. Table I gives deposition conditions of the various films used to manufacture the devices. In situ ellipsometry was used to monitor the layer growth, and to obtain growth rates. Polymer devices were manufactured by producing half-devices, which contained either the electrochromic, or the ion storage layer. The half devices were sandwiched together using the polymer layer.

Electrochemical $\mathrm{Li}^{+}$intercalation was performed in a 1.0 molar solution of $\mathrm{LiClO}_{4}$ in propylene carbonate using a potentiostat. The electrochemical cell contained a platinum foil as a counter electrode and a saturated calomel reference electrode. The potentiostat controls the voltage at the working electrode (sample) by varying the counter electrode potential. The electrochemical $\mathrm{Li}^{+}$insertion for the all-solid- 
state devices was introduced into the finished device structures through the top metal grid. In the polymer device both half devices were $\mathrm{Li}^{+}$intercalated before sticking them together.

The IR transmissive top and bottom electrode aluminum metal grids are made by photolithography. Two different sets of grid masks were used. The mask for grid 1 (fine grid) had a linewidth of $5 \mu \mathrm{m}$ and a period of $100 \mu \mathrm{m}$, whereas the mask for grid 2 (coarse grid) was made for $10 \mu \mathrm{m}$ linewidths and a $500 \mu \mathrm{m}$ line period. The transmission was calculated to be $95 \%$ and $90 \%$ for grids 1 and 2, respectively.

Prior to assembling the devices, the constituent layers were deposited as single films onto [001] silicon substrates. Glancing-angle-of incidence x-ray diffractometry (XRD) was used to study the phase content and crystallinity of the thin films. ${ }^{17,18}$

The optical properties of all device constituents were investigated by spectroscopic ellipsometry in the spectral region from 0.03 to $8.5 \mathrm{eV}(0.15-40 \mu \mathrm{m}$, vacuum ultraviolet to deep infrared). ${ }^{17-19}$ In addition, the ellipsometry data were used to determine the spectrally dependent optical dielectric function as well as the thin-film microporosity. The optical response was also measured on "half-devices," consisting of either substrate/electrode/electrochromic layer or substrate/ electrode/ion storage layer. ${ }^{14}$ With this assembly, we determined the change in the dielectric function of the electrochromic and ion storage layers after $\mathrm{Li}^{+}$insertion and extraction. The results from these optical investigations were used to build a virtual device structure, and the device emissivity modulation performance (emittance integrated over the blackbody spectrum) was simulated. In this way the device structure was optimized prior to experimental manufacture of the device. ${ }^{16}$

To study the reflectance modulation the finished real devices were electrically cycled between $+2 \mathrm{~V}$ and $-2 \mathrm{~V}$. Reflectance spectra were measured in the spectral range from 2 to $40 \mu \mathrm{m}$ using a Michelson FTIR spectrometer. Reflectance data were taken at an $11^{\circ}$ angle of incidence.

\section{MATERIALS}

Polycrystalline $\mathrm{WO}_{3}$ as-deposited films possess a monoclinic crystal structure (Fig. 1). An irreversible phase transformation occurred after $\mathrm{Li}^{+}$insertion, resulting in a cubic structure $\mathrm{Li}_{x} \mathrm{~W}_{(1-x)} \mathrm{O}_{3}$ (tungsten bronze) which changed to a tetragonal $\mathrm{Li}_{x} \mathrm{~W}_{(1-x)} \mathrm{O}_{3}$ modification after $\mathrm{Li}^{+}$extraction (Fig. 1). It has been shown elsewhere, ${ }^{20}$ that the crystal structure of tungsten bronze is a function of $\mathrm{Li}$ concentration. According to the explanation given in Ref. 20 the irreversibility of the phase transformation is caused by a certain amount of $\mathrm{Li}^{+}$, which remains in the $\mathrm{WO}_{3}$ after ion extraction. The optical properties of bleached and colored polycrystalline tungsten oxide were analyzed using infrared ellipsometry. Single films of tungsten oxide were deposited onto [001] silicon wafers and measured after coloring and bleaching. The optical properties of colored and bleached polycrystalline tungsten oxide thin films are given in Fig. 2 in terms of the real $\left(\epsilon_{1}\right)$ and imaginary $\left(\epsilon_{2}\right)$ part of the dielectric function $\epsilon$. In almost the entire spectral region $\epsilon_{1}$ and $\epsilon_{2}$ of

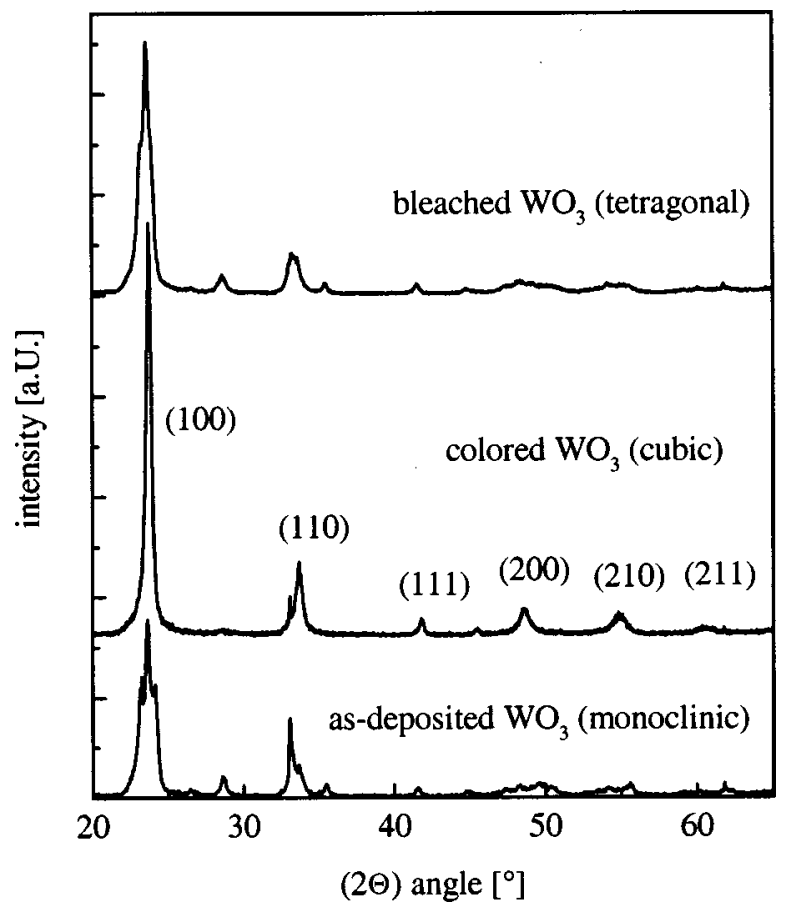

FIG. 1. Glancing-angle-of-incidence x-ray diffraction spectra taken from as-deposited, colored and bleached $\mathrm{Li}_{x} \mathrm{WO}_{3-x}$ single films on [001] Si.

the colored film is higher than that of the bleached film. There is a crossover in $\epsilon_{2}$ near $25 \mu \mathrm{m}$. A phonon absorption was found in $c-\mathrm{WO}_{3}$ near $14 \mu \mathrm{m}$. The amplitude for this absorption is much higher in the colored than in bleached $c-\mathrm{WO}_{3}$.

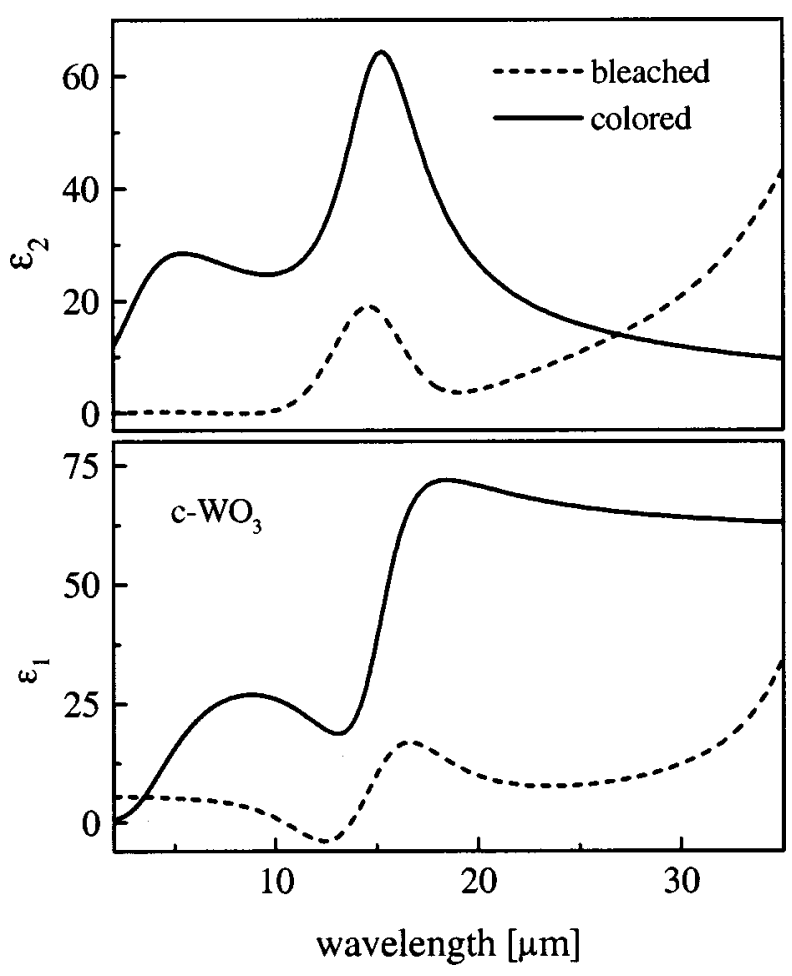

FIG. 2. IR dielectric function modulation of bleached/colored polycrystalline electrochromic $\mathrm{Li}_{x} \mathrm{WO}_{3-x}$ layer after ion extraction/insertion. 


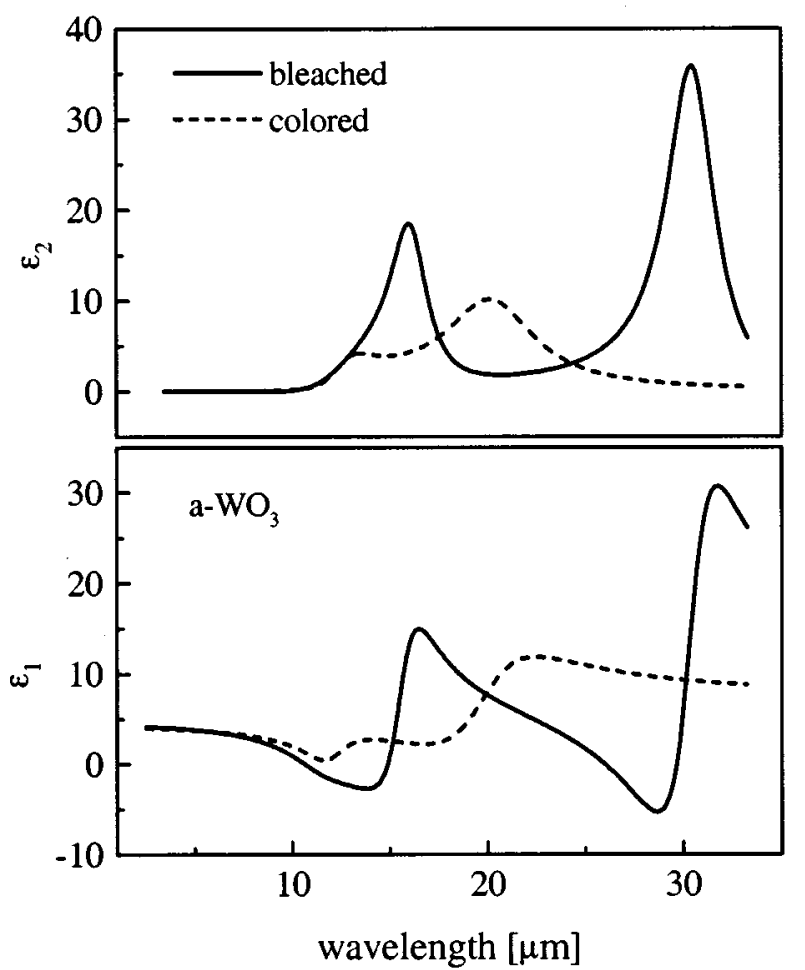

FIG. 3. IR dielectric function modulation of bleached/colored amorphous ion storage $\mathrm{Li}_{x} \mathrm{WO}_{3-x}$ layer after ion extraction/insertion.

Amorphous tungsten oxide $\left(a-\mathrm{WO}_{3}\right)$ thin films were deposited at room temperature, also on [001] silicon substrates. Their amorphous structure was verified by XRD measurements. Two phonon absorptions were found in the bleached $a-\mathrm{WO}_{3}$ near $15 \mu \mathrm{m}$ and near $30 \mu \mathrm{m}$ (Fig. 3). The phonon absorptions became much weaker upon $\mathrm{Li}^{+}$intercalation and moved in spectral position to 13 and $20 \mu \mathrm{m}$, respectively. However even though there was a change in the optical properties of $a-\mathrm{WO}_{3}$ upon $\mathrm{Li}^{+}$insertion and extraction, the $\epsilon_{1}$ and $\epsilon_{2}$ modulation is much weaker for $a-\mathrm{WO}_{3}$ than for $c-\mathrm{WO}_{3}$. The coloration effect after $\mathrm{Li}^{+}$insertion into $a-\mathrm{WO}_{3}$ was also studied by Burdis et $a l .{ }^{21}$ using FTIR spectroscopy.

The tantalum oxide thin films were amorphous when deposited in our typical deposition regime. However the deposition process was optimized with respect to microporosity of the thin films. There are especially high quality requirements for the ion conductor layer material, because pinholes in this layer can cause unwanted electrical conductivity between the electrochromic and ion storage layers resulting in a failure in device operation. Tantalum oxide thin films deposited at temperatures higher than $200^{\circ} \mathrm{C}$ and oxygen flux rates above 7 sccm showed a considerably smaller microporosity. ${ }^{18}$ The optical properties of tantalum oxide thin films are given in Fig. 4.

ITO or aluminum (Al) was used as the electrode material. Electrically conducting materials have Drude-like optical behavior (free carrier effects) at long wavelengths. Thin film optical properties of ITO and $\mathrm{Al}$ were also determined by ellipsometry.

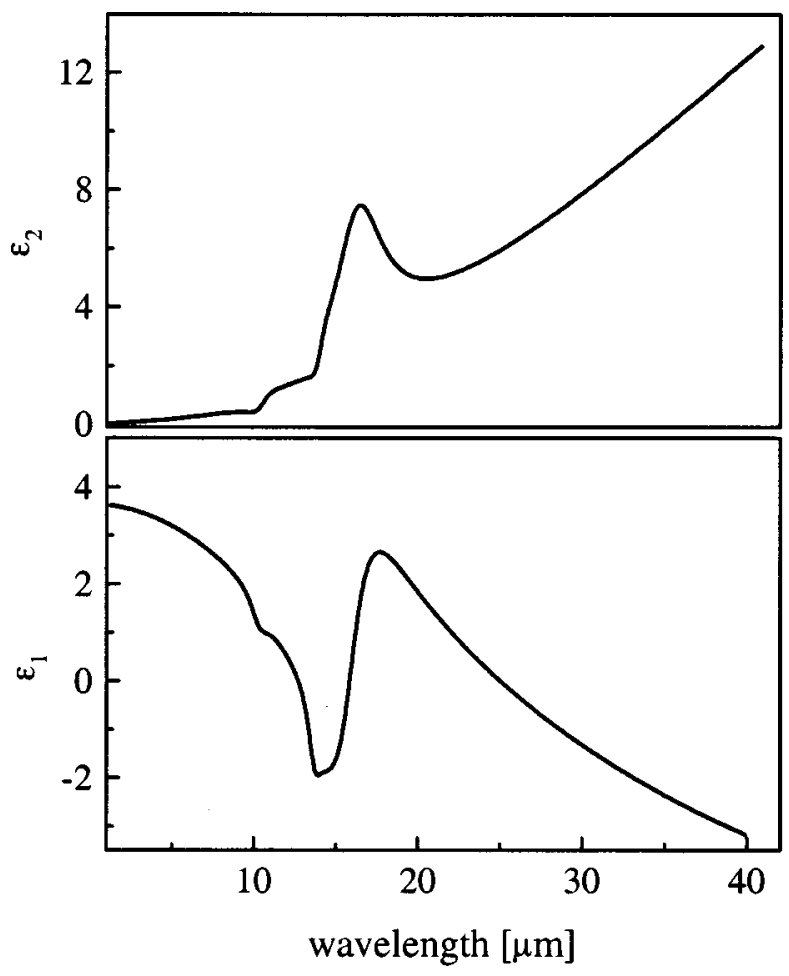

FIG. 4. IR dielectric function of the $\mathrm{Ta}_{x} \mathrm{O}_{y}$ ion conductor.

\section{RESULTS AND DISCUSSION}

Prior to device manufacture we simulated the emittance modulation for devices with different layer structures. A possible structure for an all-solid state device is shown in Fig. 5. In this case the bottom electrode can be a coalescent aluminum metal layer (single-grid device) or an aluminum metal grid (double-grid device). The two device types function in different ways. Whereas the single-grid device operates on

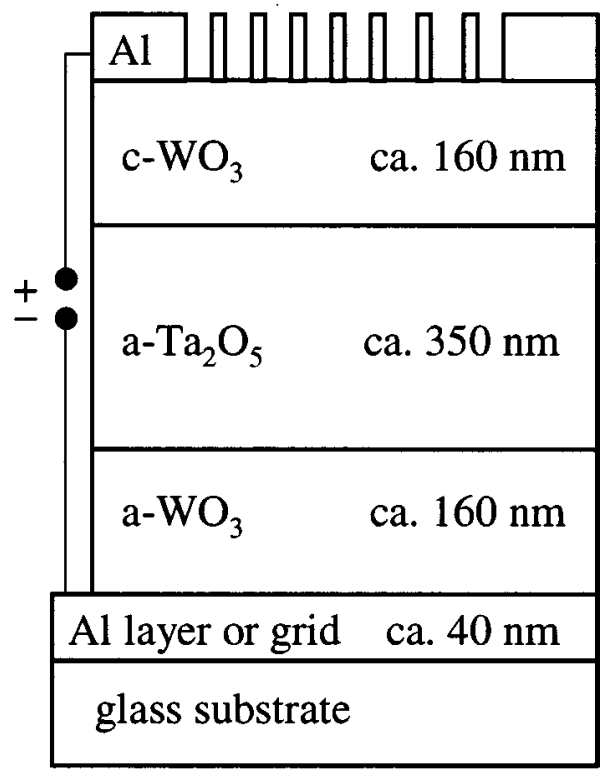

FIG. 5. Layer structure of the all-solid-state electrochromic devices for thermal emittance modulation in the spectral region from 2 to $35 \mu \mathrm{m}$. The bottom electrode consists of either a continuous $\mathrm{Al}$ metal layer or an $\mathrm{Al}$ metal grid. 


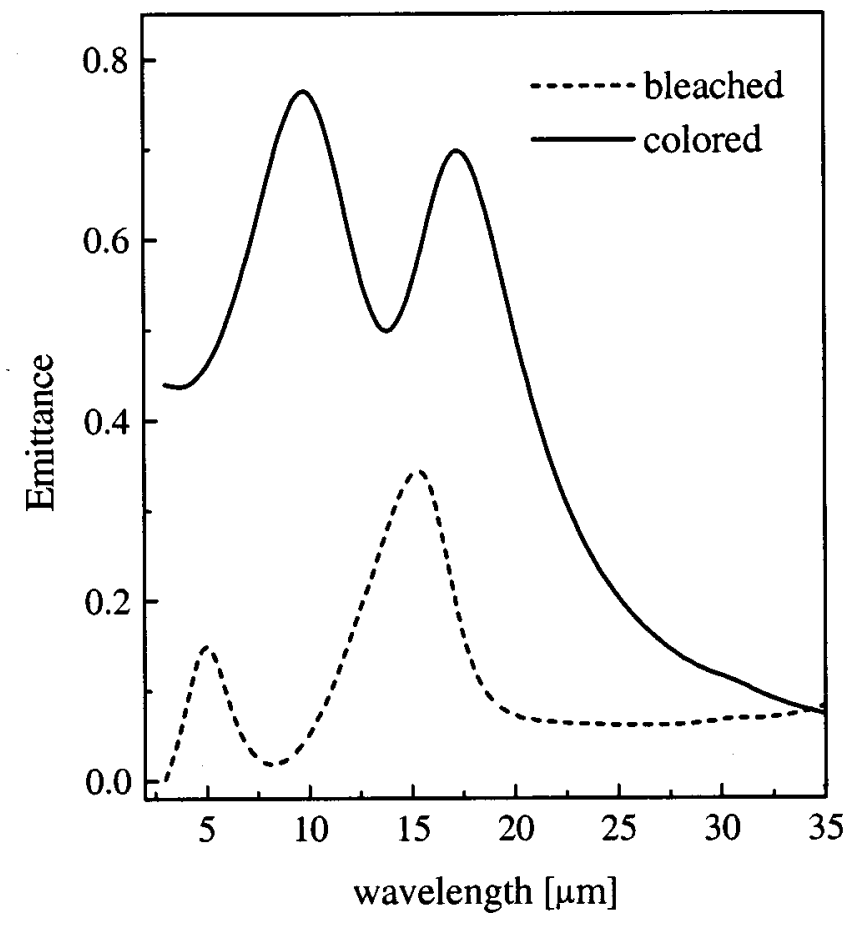

FIG. 6. Emittance modulation simulation in the spectral region from 2 to 35 $\mu \mathrm{m}$ for a single-grid electrochromic device with layer structure shown in Fig. 5.

the basis of reflectance modulation, the double-grid device works by modulation of the substrate emission. The results of the device performance simulations in terms of emittance modulation are given in Fig. 6 for the single-grid device, and in Fig. 7 for the double-grid all-solid state device. In the

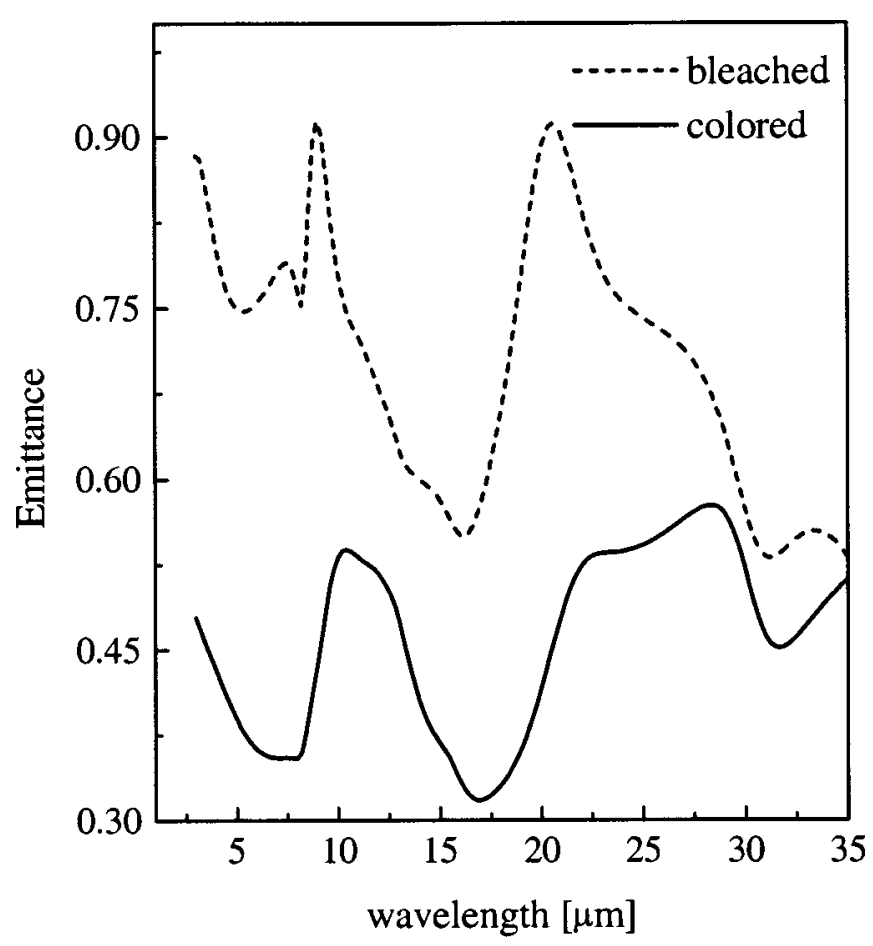

FIG. 7. Emittance modulation simulation in the spectral region from 2 to 35 $\mu \mathrm{m}$ for a double-grid electrochromic device with layer structure shown in Fig. 5.

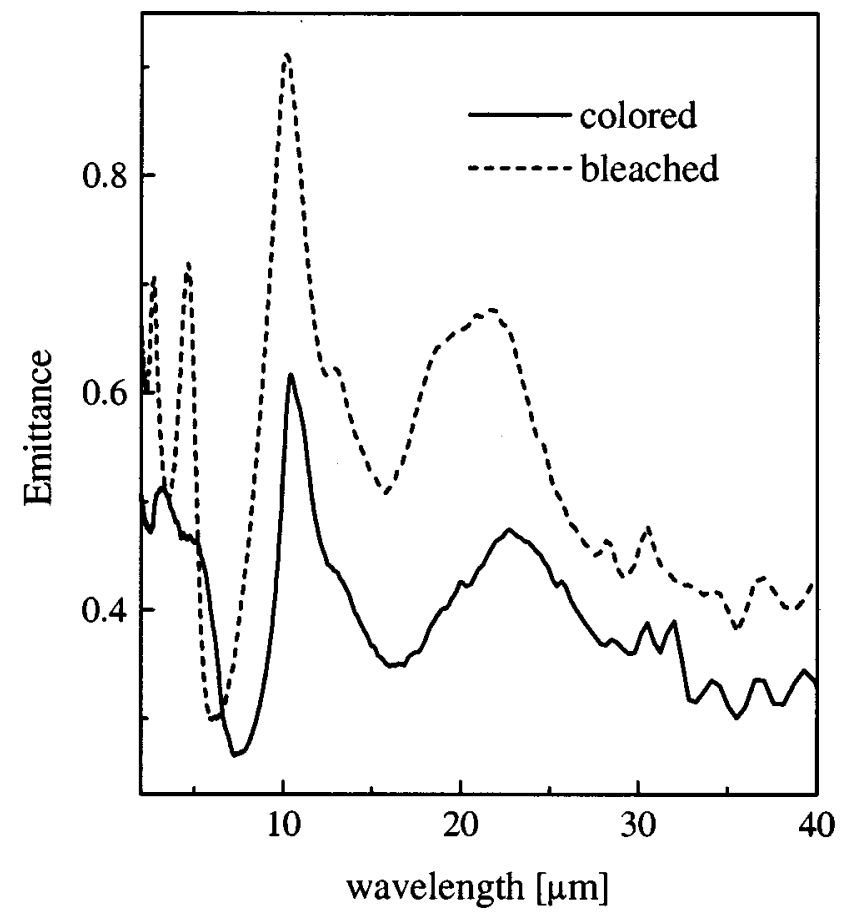

FIG. 8. Emittance modulation of the single-grid electrochromic device for thermal emissivity modulation for wavelength from 2 to $40 \mu \mathrm{m}$.

reflectance modulation based single-grid device the bleached state refers to the low emittance condition, and the colored state to the high emittance condition. The integrated emissivity $\epsilon$ [Eq. (1)] of the colored and bleached device states found from integration over the blackbody spectrum at 300 $\mathrm{K}$ are 0.45 and 0.88 , respectively. This corresponds to a total emissivity modulation of $43 \%$ and an emissivity ratio of 1.94 .

The double-grid device operates in the opposite way to the single-grid device. Here, the bleached state refers to the high emittance state, and the colored state represents the low emittance state. The integrated emissivity is calculated to be 0.28 and 0.56 for the colored and bleached state, respectively. The total emissivity modulation is $28 \%$ and therefore smaller than the emissivity modulation for the single-grid device. The emissivity ratio obtained was 1.98 .

All-solid state electrochromic devices were manufactured according to the device structures proposed in the emittance modulation simulations. The emittance modulation of a single-grid device is given in Fig. 8. The devices were cycled between $+2 \mathrm{~V}$ (bleached) and $-2 \mathrm{~V}$ (colored) several times, reversibly reaching the low and high emissivity states. However devices exposed to atmosphere for more than two days lead to device failure. We assume that the $\mathrm{Li}^{+}$reacted with atmospheric nitrogen or oxygen and became immobile. There were strong lattice absorptions in the device response just above $10 \mu \mathrm{m}$. From IR optical data it is known that the characteristic lattice absorptions of the metal oxides $\left(c-\mathrm{WO}_{3}, a-\mathrm{WO}_{3}, a-\mathrm{Ta}_{2} \mathrm{O}_{5}\right)$ are localized in this spectral region. These strong absorptions in the entire device are therefore due to a sum of lattice absorption contributions from each metal oxide layer. To improve device performance the absorption broadening can be reduced by using smaller layer 
thicknesses, or higher material perfection. There is additional reflectance modulation due to thickness interference effects in the spectral region from 15 to $40 \mu \mathrm{m}$, which are mainly caused by the $a-\mathrm{Ta}_{2} \mathrm{O}_{5}$ ion conductor layer. To remove these interference effects a thinner layer should be used. However, devices with thinner $\mathrm{Ta}_{2} \mathrm{O}_{5}$ layer thickness usually failed because of electrical shorts between ion storage and electrochromic layers. Further attempts to improve the ion conductor structural properties should help solve this problem and allow optimizing the $\mathrm{Ta}_{2} \mathrm{O}_{5}$ layer thickness to limit interference effects.

The emissivity in the low- and the high-emittance state integrated over the $300 \mathrm{~K}$ blackbody spectra was calculated from the reflectance spectra measured in the devices bleached and colored states, and found to be 0.4 and 0.58 , respectively. This results in emissivity modulation of $18 \%$ and an emissivity ratio of 1.45 . This is a much lower emissivity modulation than expected from our simulations. One reason might be a nonuniform $\mathrm{Li}^{+}$depth distribution. Thus a $\mathrm{Li}^{+}$depth profile was measured by secondary neutral mass spectroscopy (SNMS). The SNMS profile showed a high concentration of $\mathrm{Li}^{+}$captured at each interface between adjacent layers. It also showed a nonuniformity in the Li distribution which had a concentration maxima at the interfaces and minima in the middle of the layer. After device switching a certain amount of $\mathrm{Li}^{+}$always remained in the layer (electrochromic or ion storage) which was supposed to be $\mathrm{Li}$ free, or it was stacked in the tantalum oxide ion conductor layer. The nonideal Li distribution is likely the major difference between the idealized simulated device performance and the real experiments.

The modulation performance of the single-grid device also did not follow predictions from simulations. In the simulation it was shown that the device bleached and colored states refer to the low and high emissive conditions, respectively. However, the single-grid device performance experimentally shows the opposite behavior. An explanation could be that a certain amount of $\mathrm{Li}^{+}$ions remain in the electrochromic layer after ion extraction and the device switches only between a higher and a lower reflecting electrochromic top $c-\mathrm{WO}_{3}$ layer. If this is the case incident light may not reach the bottom electrode where it should be reflected in the devices bleached state according to our simulations.

The performance of a double-grid electrochromic device is given in Fig. 9. Again there was a strong absorption due to phonon vibrations centered just above $10 \mu \mathrm{m}$, and absorptions due to thickness interference effects. The integrated emissivity of the device in its bleached and colored states was calculated to be 0.8 and 0.64 . This resulted in an emissivity modulation of $16 \%$ and an emissivity ratio of 1.26 . The double-grid device had a somewhat smaller performance range than the single-grid device predicted by simulations. However, in the case of the double-grid device the modulation followed the same switching behavior as shown in the simulations, having the bleached and the colored states as the high and low emissive conditions, respectively. The difference in the dynamic modulation range between simulation and experiment can be explained in the same way as for the

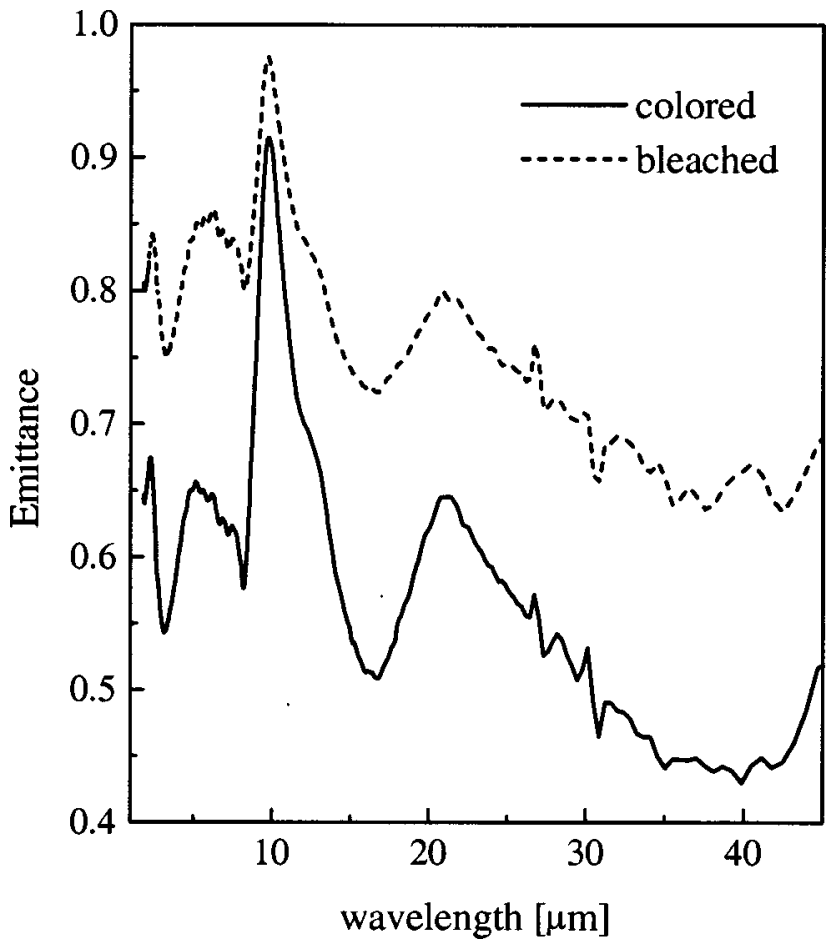

FIG. 9. Emittance modulation of the double-grid electrochromic device for thermal emissivity modulation for wavelength from 2 to $45 \mu \mathrm{m}$.

single-grid device, namely that ions possibly do not move uniformly between layers.

$c-\mathrm{WO}_{3}$ has been exposed to atomic oxygen under UV radiation in order to test the materials reliability in space environment. Investigations showed a degradation and a blue coloring of $c-\mathrm{WO}_{3}$. For that reason a simulation was made to test the electrochromic device performance with a protection layer on top of the top electrode metal grid. The same device structure was used as for the single-grid device modulation simulations. Several materials have been tested in the simulation, whereas a $600 \mathrm{~nm} \mathrm{ZnS}$ coating showed the most promising optical switching results (Fig. 10). According to the simulation the overcoat layer fulfills a twofold purpose; first it serves as a protection layer for the highly reactive $\mathrm{Li}^{+}$ and $c-\mathrm{WO}_{3}$, and second it improves the device performance in the spectral region of interest. For a $\mathrm{ZnS}$ overcoat the emissivity integrated over the $300 \mathrm{~K}$ blackbody was calculated to be 0.61 and 0.13 in the devices colored and bleached states, which results in an emissivity modulation of $48 \%$ and an emissivity ratio of 4.56. Similar simulations have been performed using $900 \mathrm{~nm}$ thick $\mathrm{MgF}_{2}$ as a device cap layer, since there are some doubts about the stability of $\mathrm{ZnS}$ in space. $\mathrm{MgF}_{2}$ is a material often used for optical coatings and easy to deposit. Simulated performance of a device with a $\mathrm{MgF}_{2}$ overcoat is shown in Fig. 11. $\mathrm{MgF}_{2}$ is uniaxial, and both ordinary and extraordinary optical constant spectra were isotropic averaged to simulate the optical response of a polycrystalline layer with randomly oriented grains. The emissivity modulation again integrated over the $300 \mathrm{~K}$ blackbody was obtained to be $29 \%$ and the emissivity ratio was 2.82 . As can be seen in Fig. 11 the modulation maximum for a $\mathrm{MgF}_{2}$ covered device is near $6 \mu \mathrm{m}$ therefore this kind of device is 


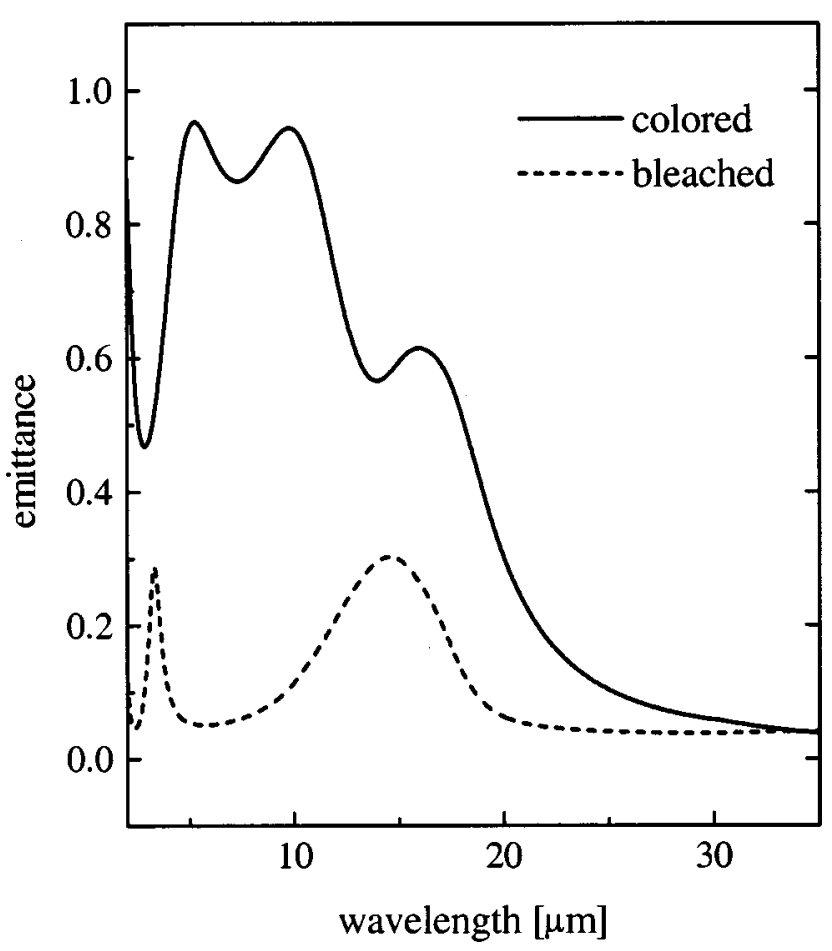

FIG. 10. Simulated device performance for a single-grid electrochromic device with a $\mathrm{ZnS}$ protection coating on top of the $\mathrm{Al}$ metal grid.

just right for high temperature applications. Emissivity modulation and ratio calculated by integration over the 600 and $900 \mathrm{~K}$ blackbody spectra were obtained to be $52 \%$ and 4.88, and $50 \%$ and 5.2. Space stability of $\mathrm{MgF}_{2}$ will be investigated in the future by sample exposure to atomic oxygen and UV radiation in a special plasma chamber.

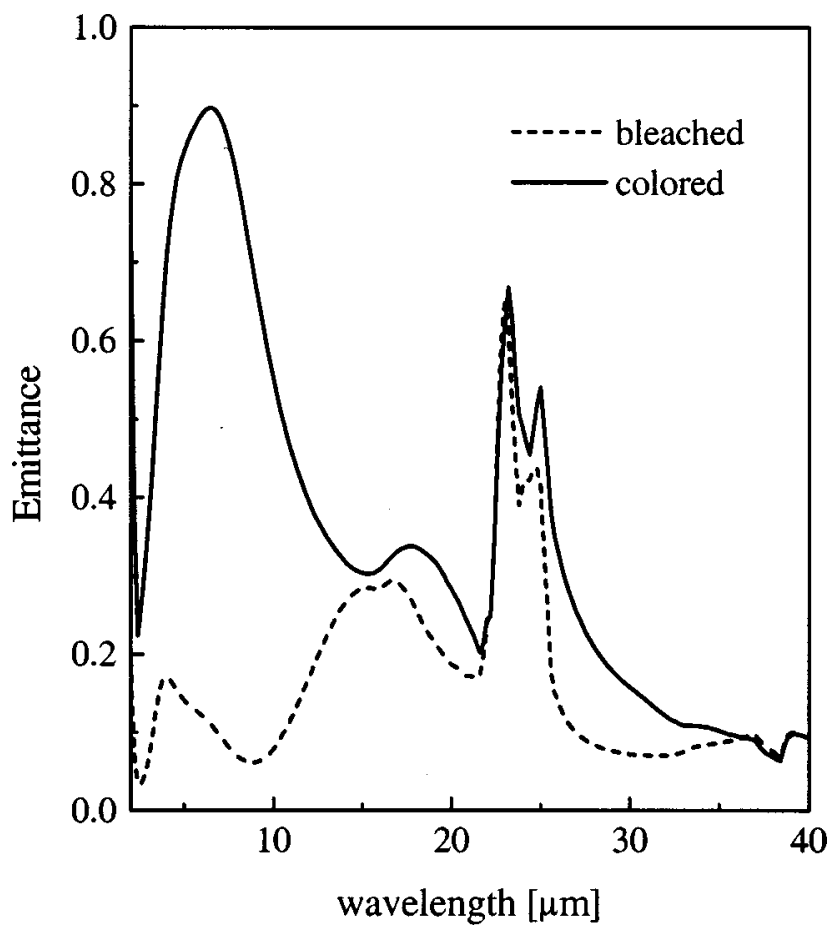

FIG. 11. Simulated device performance for a single-grid electrochromic device with a $\mathrm{MgF}_{2}$ protection coating on top of the $\mathrm{Al}$ metal grid.

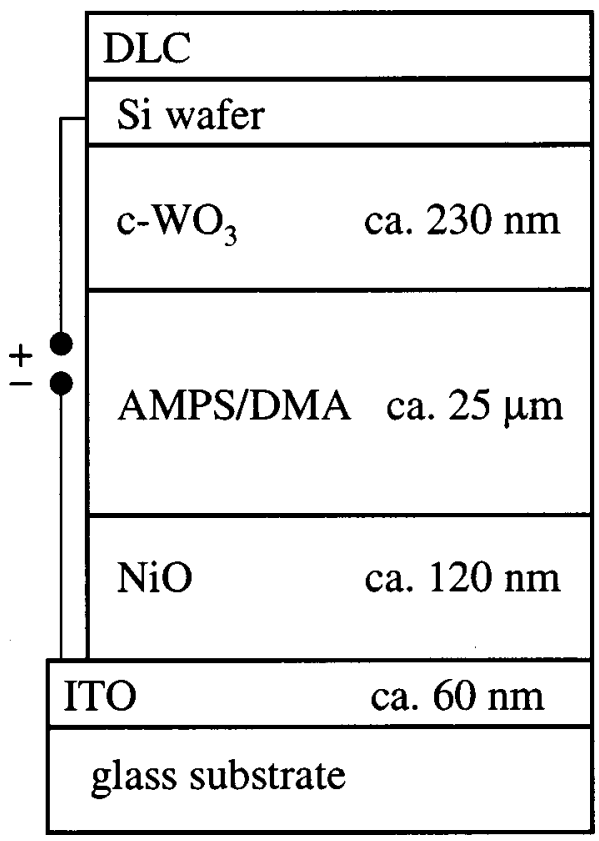

FIG. 12. Layer structure of the polymer electrochromic device for thermal emittance modulation in the spectral region from 2 to $35 \mu \mathrm{m}$. A DLC antireflecting coating is deposited on top of the slightly doped silicon substrate to improve the emissivity modulation.

A third structure for an emissivity modulating electrochromic device is shown in Fig. 12. Here a highly absorbing/ emissive AMPS/DMA polymer ion conductor was used. A DLC coating was deposited on top of the low-doped silicon substrate to improve device performance. For this device type the emissivity modulation was caused only by the change in optical properties of the $c-\mathrm{WO}_{3}$-top layer, since

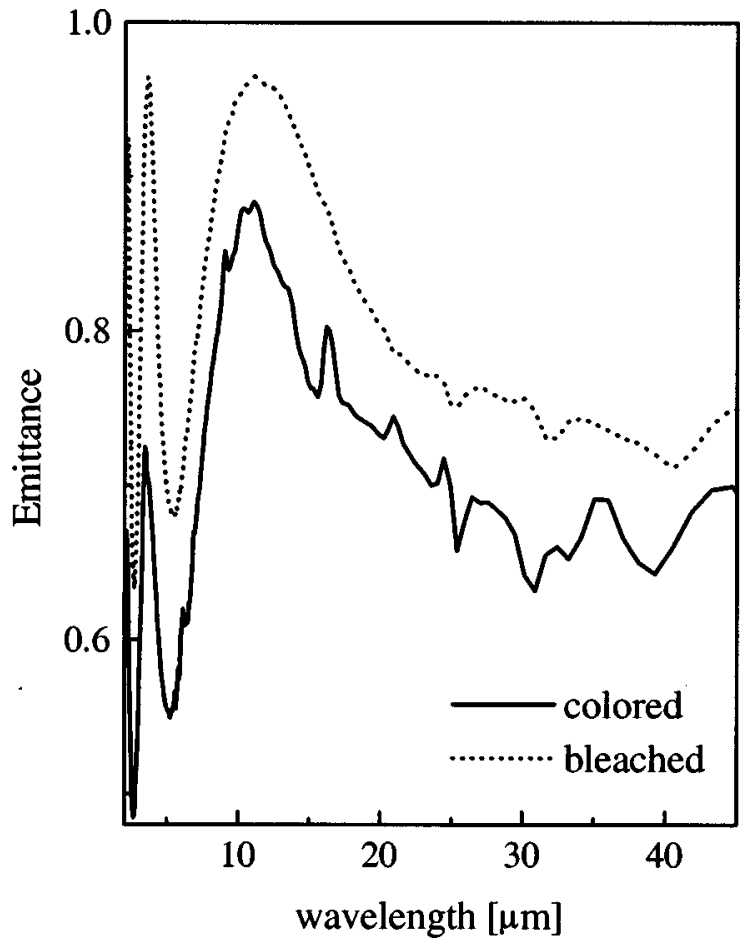

FIG. 13. Emittance modulation of the polymer electrochromic device for thermal emissivity modulation for wavelength from 2 to $45 \mu \mathrm{m}$. 
TABLE II. Calculated and experimentally measured device performance for the single and double-grid all-solid state devices and the polymer device; $\epsilon_{\text {bleached }}$ and $\epsilon_{\text {colored }}$ are the calculated emissivity values of the device in its bleached and colored states integrated over the $300 \mathrm{~K}$ blackbody spectra, $\epsilon_{\text {ratio }}$ and $\epsilon_{\text {modulation }}$ give the ratio and the difference between the high and the low emissivity states of the device.

\begin{tabular}{lcccc}
\hline \multicolumn{1}{c}{ Device type } & $\epsilon_{\text {bleached }}$ & $\epsilon_{\text {colored }}$ & $\epsilon_{\text {modulation }}(\%)$ & $\epsilon_{\text {ratio }}$ \\
\hline $\begin{array}{l}\text { Single-grid simulation } \\
\text { device }\end{array}$ & 0.45 & 0.88 & 43 & 1.94 \\
$\begin{array}{l}\text { Double-grid simulation } \\
\text { device }\end{array}$ & 0.56 & 0.28 & 28 & 1.98 \\
$\begin{array}{l}\text { Single-grid experimental } \\
\text { device }\end{array}$ & 0.58 & 0.4 & 18 & 1.45 \\
$\begin{array}{l}\text { Double-grid experimental } \\
\text { device }\end{array}$ & 0.8 & 0.64 & 16 & 1.26 \\
$\begin{array}{l}\text { Single-grid simulation } \\
\quad \text { device with ZnS coating }\end{array}$ & 0.13 & 0.61 & 48 & 4.56 \\
$\begin{array}{l}\text { Single-grid simulation } \\
\text { device with MgF }\end{array}$ \\
$\quad 0.17$ & 0.46 & 29 & 2.66 \\
$\begin{array}{l}\text { Single-grid simulation } \\
\text { device with } \mathrm{MgF}_{2} \text { coating } \\
\quad(600 \mathrm{~K} \text { blackbody) }\end{array}$ & 0.13 & 0.65 & 52 & 4.88 \\
$\begin{array}{l}\text { Single-grid simulation } \\
\text { device with } \mathrm{MgF}_{2} \text { coating } \\
\quad(900 \mathrm{~K} \text { blackbody) }\end{array}$ & 0.12 & 0.62 & 50 & 5.2 \\
$\begin{array}{l}\text { Polymer experimental } \\
\text { device }\end{array}$ & 0.86 & 0.76 & 10 & 1.1 \\
\hline \hline
\end{tabular}

the layers underneath the absorbing ion conductor could not contribute to the reflectance spectra of the device. The experimental effort needed to manufacture this device type is higher than for the all-vacuum-solid state devices. The emittance modulation for the polymer device is given in Fig. 13. The emissivity for the bleached and colored states integrated over the $300 \mathrm{~K}$ blackbody is 0.86 and 0.76 , respectively, corresponding to an emissivity modulation of $10 \%$ and an emissivity ratio of 1.1 . The calculated values for simulated and experimentally measured device performances for all three device types are summarized in Table II.

\section{CONCLUSIONS}

The design and performance of three different types of EMDs, two all-solid state devices (single- and double-grid device) and a polymer-based device have been discussed. Polycrystalline $c-\mathrm{Li}_{x} \mathrm{~W}_{1-x} \mathrm{O}_{3}$ and amorphous $a-\mathrm{Li}_{x} \mathrm{~W}_{1-x} \mathrm{O}_{3}$ (or $\mathrm{NiO}$ for the polymer device) have been used as electrochromic and ion storage layers, respectively. Tantalum oxide was used as an ion conductor in the all-solid state devices. The infrared optical constants for all device constituents have been obtained by spectroscopic ellipsometry. The results have been used to model virtual devices, thus allowing simulation of the reflectance modulation between the colored and bleached states of the device and thereby predicting the device performance. These devices were experimentally manufactured and had the same structure as used for the simulations. The range of device operation was investigated for the spectral region from 2 to $40 \mu \mathrm{m}$. The simulated and experimentally measured reflectance spectra in the spectral region from 2 to $40 \mu \mathrm{m}$ were used to calculate the emissivity modulation of the device integrated over the $300 \mathrm{~K}$ blackbody emissivity spectra. Simulations and experiment showed the best device performance for the single-grid device, although simulations predict an opposite switching behavior than found experimentally. The double-grid device emissivity modulation was mostly limited by the strong phonon absorption near $10 \mu \mathrm{m}$, which is unfortunately just above the peak maximum of the $300 \mathrm{~K}$ blackbody spectra. All devices introduced in this work were switched for several cycles, reaching the low and high emissive state reversibly.

\section{ACKNOWLEDGMENTS}

The authors thank D. W. Thompson at University of Nebraska-Lincoln for technical help and valuable discussions. Furthermore, we gratefully acknowledge K. Zimmer and E. Salamatin at Institut für Oberflächenmodifizierung Leipzig for providing the grid masks. We would like to thank Tariqul Islam for technical guidance during photolithography. The work was supported by BMDO Grant No. DSAG60-98-C-0054, NASA Glenn Research Center Grant No. NAG3-2219, and NASA Epscor Grant No. NCC5-169.

${ }^{1}$ C. G. Granqvist, Handbook of Inorganic Electrochromic Materials (Elsevier, Amsterdam, 1995).

${ }^{2}$ C. L. Trimble, E. Franke, J. S. Hale, and J. A. Woollam, Proceedings of Space Technology and Applications International Forum, edited by M. S. El-Genk (2000), p. 797.

${ }^{3}$ A. G. Darrin, R. Osiander, J. Champion, T. Swanson, and D. Douglas, Proceedings of Space Technology and Applications International Forum, edited by M. S. El-Genk (2000), p. 803.

${ }^{4}$ L. M. Grob and T. D. Swanson, Proceedings of Space Technology and Applications International Forum, edited by M. S. El-Genk (2000), p. 809.

${ }^{5}$ D. G. Gilmore, Satellite Thermal Control Handbook (The Aerospace Corporation, El Segundo, CA, 1994), p. 4.

${ }^{6}$ R. B. Goldner and R. D. Rauh, Proc. SPIE 428, 38 (1983).

${ }^{7}$ R. B. Goldner, F. Arntz, G. Berera, T. E. Haas, G. Wei, K. K. Wong, and P. Yu, Proc. SPIE 1536, 34 (1991).

${ }^{8}$ S. F. Cogan, T. D. Plante, M. A. Parker, and R. D. Rauh, J. Appl. Phys. 60, 2735 (1986)

${ }^{9}$ S. F. Cogan, R. D. Rauh, J. D. Klein, and T. D. Plante, Proc. SPIE 1149, 2 (1989)

${ }^{10}$ C. G. Granqvist, Sol. Energy Mater. Sol. Cells 60, 201 (2000).

${ }^{11}$ C. G. Granqvist, Appl. Phys. A: Solids Surf. 52, 83 (1991).

${ }^{12}$ K. Baucke, Sol. Energy Mater. 16, 67 (1987).

${ }^{13}$ P. Topart and P. Hourquebie, Thin Solid Films 352, 243 (1999).

${ }^{14}$ C. L. Trimble, M. J. DeVries, J. S. Hale, D. W. Thompson, T. E. Tiwald, and J. A. Woollam, Thin Solid Films 347, 1 (1999).

${ }^{15}$ S. F. Cogan, R. D. Rauh, J. D. Klein, and T. D. Plante, Electrochemical Society Proceedings (Electrochemical Society, Pennington, NJ, 1995), Vol. 94-2, p. 269

${ }^{16}$ J. S. Hale and J. A. Woollam, Thin Solid Films 339, 174 (1999).

${ }^{17}$ M. J. DeVries, C. L. Trimble, T. E. Tiwald, D. W. Thompson, J. A. Woollam, and J. S. Hale, J. Vac. Sci. Technol. A 17, 2906 (1999).

${ }^{18}$ E. Franke, M. Schubert, C. L. Trimble, M. J. DeVries, J. S. Hale, J. A. Woollam, and F. Frost, J. Appl. Phys. (submitted).

${ }^{19}$ J. S. Hale, M. J. DeVries, B. Dworak, and J. A. Woollam, Thin Solid Films 313-314, 205 (1998).

${ }^{20}$ Q. Zhong, J. R. Dahn, and K. Colbow, Phys. Rev. B 46, 2554 (1992).

${ }^{21}$ M. S. Burdis, J. R. Siddle, and S. Taylor, Proc. SPIE 2255, 371 (1994). 